\title{
"On the Rocks"
}

\section{CLEMENTINA TEIXEIRA, ANTONIETA SANTANA E CONCEIÇÃO MESQUITA ${ }^{1}$}

\section{INTRODUÇ̃̃o}

Se o leitor pensa que the vamos dar a receita de um novo cocktail engana-se: vamos sim proporcionar-Ihe um aperitivo atractivo para o ensino da Química básica e não só, quiçá um novo passatempo que pode compartilhar com os seus filhos e amigos. A ideia é simples e de resultados rápidos: trata-se de recristalizar sobre pedras e outros materiais tais como conchas, arame, redes metálicas e vidro, produtos químicos de cores diversas, capazes de desenvolver cristais com relativa facilidade. Apenas se ensaiaram sais iónicos de metais de transição solúveis em água. Tenciona-se, porém, numa fase posterior, estender este trabalho a compostos orgânicos e complexos de metais de transição, empregando outros solventes e técnicas mais sofisticadas.

0 impacto deste método foi enorme quando testado a diversos niveis, desde a criancinha de tenra idade, até ao colega Professor Universitário, passando pelo aluno do $1^{\circ}$ ano de Química Geral da Universidade para quem, invariavelmente, a Química é um fardo demasiado pesado de transportar. Hoje em dia as rochas ornamentais estão na moda e a ocupação de tempos livres com "hobbies" diversos também. É comum num passeio à montanha ou à praia, adultos e crianças ocuparem-se frequentemente na recolha de conchas e pedras que ficam como recordações disto e daquilo. Estas são, na nossa opinião, as causas próximas para que esta ideia tenha ampla aceitação. Os mais pacientes e amantes do perfeccionismo, terão aqui a oportunidade de aperfeiçoar as receitas que abaixo se descrevem, na tentativa de obter cristais ainda maiores, de substâncias com cores mais exóticas ou mais dificeis de cristalizar. Para aqueles que nele pensam com um cifrão em cada olho uma advertência que, na realidade, é geral: o método obriga a manusear compostos tóxicos em elevado alergias, dermatites e conjuntivites, para não falar em envenenamentos! Siga portanto à risca os conselhos que aqui se dão para evitar situações desagradáveis e prefira um laboratório para local de execução deste trabalho.

Para finalizar, não pretendemos reinvidicar a originalidade do método: na realidade ele é usado com fins lucrativos na Sicilia, ou seja, para explorar os turistas visitantes do vulcão Etna que, inadvertidamente, ou por falta de conhecimentos em Química, confundem pedaços de magma ornamentado com cristais de sulfato de cobre com rochas verdadeiras. Apenas pretendemos, como pessoas que se interessam pelo ensino, divulgar a Química de uma forma atractiva e menos penosa na sua aprendizagem.

\section{OS COMPOSTOS E AS PEDRAS, 0 QUE ESCOLHER?}

Os processos de crescimento de cristais são objecto de contínua pesquisa, como o comprovam as inúmeras publicações sobre 0 assunto $[1,2]$. Este método, ou seja, a recristalização sobre pedras e outros materiais, permite obter cristais bem desenvolvidos de forma rápida, simples e atractiva em apenas algumas horas, com material corrente de laboratório, por simples arrefecimento de soluções saturadas. Os cristais podem, em alguns casos, atingir dimensões consideráveis (dois a três centimetros). Este processo poderá ainda permitir obter cristais de maiores dimensões por optimização das condições de arrefecimento e concentrações utilizadas para cada tipo de rocha. As pedras deverão ser rugosas e de superfície irregular para estimular a cristalização, proporcionando assim, sobre a sua superfície , grande número de núcleos para crescimento de cristais. Mármore sem polimento, calcário comum de calcetar as ruas, granito, cimento, basalto e em especial lava consolidada, foram os materiais ensaiados. Poder-se-á também utilizar pedra-pomes, que deverá ser fixada com cola no fundo do cristalizador, evitando que venha para a superficie, devido à sua baixa densidade. Tal como já se indicou, também se pode utilizar como suporte fragmentos, tubos ou varetas de vidro, arames e rede de metal.

Foram testados os seguintes compostos, todos solúveis em água e suas misturas:
1 - $\mathrm{CuSO}_{4} \cdot 5 \mathrm{H}_{2} \mathrm{O}$ (azul) ou $\mathrm{CuSO}_{4}$ anidro*;

2 - $\mathrm{NiSO}_{4} \cdot 6 \mathrm{H}_{2} \mathrm{O}$ (verde) ${ }^{\star \star}$;

3 - $\mathrm{Cu}\left(\mathrm{CH}_{3} \mathrm{COO}\right)_{2} \cdot \mathrm{H}_{2} \mathrm{O}$ (azul escuro esverdeado) ${ }^{* *}$;

4 - $\mathrm{Co}\left(\mathrm{CH}_{3} \mathrm{COO}\right)_{2} \cdot 4 \mathrm{H}_{2} \mathrm{O}$ (rosa avermelhado) ;

5 - $\left(\mathrm{NH}_{4}\right)_{2} \mathrm{Cu}\left(\mathrm{SO}_{4}\right)_{2} \cdot 6 \mathrm{H}_{2} \mathrm{O}$ (azul claro):

6 - $\left(\mathrm{NH}_{4}\right)_{2} \mathrm{Ni}\left(\mathrm{SO}_{4}\right)_{2}, 6 \mathrm{H}_{2} \mathrm{O}$ (verde), Figura a);

7 - $\left(\mathrm{NH}_{4}\right)_{2} \mathrm{Co}\left(\mathrm{SO}_{4}\right)_{2} \cdot 6 \mathrm{H}_{2} \mathrm{O}$ (rosa avermeIhado), Figura b);

$8-\mathrm{K}_{3}\left[\mathrm{Fe}(\mathrm{CN})_{6}\right]$ (vermelho), Figura c);

9- $\mathrm{K}_{4}\left[\mathrm{Fe}(\mathrm{CN})_{6}\right] \cdot 3 \mathrm{H}_{2} \mathrm{O}$ (amarelo) ${ }^{\star *}$ Alúmens de fórmula geral $\mathrm{M}^{\prime} \mathrm{M}^{\mathrm{in}}$ $\left(\mathrm{SO}_{4}\right)_{2} \cdot 12 \mathrm{H}_{2} \mathrm{O}$

10 - alúmen de potássio, $M^{\prime}=K, M^{\prime \prime \prime}=A l$ (incolor), Figura d);

11 - alúmen de ferro, $\mathrm{M}^{\prime}=\mathrm{NH}_{4}^{+}, \mathrm{M}^{\mathrm{III}}=\mathrm{Fe}$ (amarelo pálido) ${ }^{\star \star}$, Figura e);

12 - alúmen de crómio, $M^{\prime}=K, M^{\prime \prime \prime}=C r$, (vermelho escuro quase preto) ${ }^{*}$;

Misturas de sais:

13 - 1 e 2 (todos os tons de mistura do azul e do verde $)^{\star \star}$

14 - 1 e 10 (ténue cor de azul);

$15-1$ e 11 (verde) ${ }^{\star *}$

16 - 10 e 12 (cor de ametista), Figura f);

$17-2$ e 11 (verde) $)^{\star *}$

$18-1,10$ e 12

$19-1,2$ e $12^{*}$ 
Para as soluções mistas contendo mais do que um metal, verificou-se que, em alguns casos, os compostos ensaiados podem formar soluções sólidas, dependendo da semelhança dos respectivos sistemas de cristalização. 0 caso mais espectacular é 0 das misturas de alúmens de crómio e de potássio (16), em quaisquer proporções, com cristais bem desenvolvidos, dado que possuem o mesmo sistema de cristalização, o cúbico. No caso da mistura 14 , os sistemas já são diferentes e a solubilidade do sulfato de cobre (sistema triclínico) no alúmen de potássio é baixa, como se conclui pela ténue cor azul dos cristais obtidos, com dimensões apreciaveis e cristalizando de forma idêntica à do alúmen de potássio. A mistura de três componentes (18), ou seja, os alúmens de crómio, potássio e 0 sulfato de cobre, apresenta uma mistura de dois tipos de cristais: pequenos de cor levemente azul, e grandes, cor de ametista, demonstrando a dita preferência por sistemas de cristalização semelhantes. Outro exemplo é o das misturas 13 , sulfatos de cobre e de níquel: formam soluções sólidas com cristais bem desenvolvidos, com um sistema de cristalização completamente diferente do do niquel. Nas misturas destes dois sulfatos com 0 alúmen de crómio (mistura 19), verificou-se, por observação ao microscópio, que apenas se formam cristais pouco desenvolvidos de cor verde (níquel e cobre) e que o crómio cristaliza à parte. Também é de realçar que, aparentemente, e pelo tamanho dos cristais obtidos, a solubilidade dos sulfatos de cobre e de níquel em alúmen de ferro é muito maior do que em alúmen de potássio, misturas 15 e 17 , respectivamente. Estas misturas ou/e soluções, reflectem as propriedades dos seus componentes: por exemplo. todas as composições de sulfato de níquel são eflorescentes, embora menos do que o sal puro. É comum, aliás, a composição deste sal vir indicada como $\mathrm{NiSO}_{4} \cdot \mathrm{xH}_{2} \mathrm{O}$, frisando bem este carácter.

Ao fazer soluçōes aquosas destes sais, formam-se os catiões hidratados $\left[\mathrm{M}\left(\mathrm{H}_{2} \mathrm{O}\right)_{6}\right]^{\mathrm{n}+}$ que, como se sabe, são ácidos de Brönsted, sofrendo a protólise

$$
\left[M\left(\mathrm{H}_{2} \mathrm{O}\right)_{6}\right]^{\mathrm{n}+}+\mathrm{H}_{2} \mathrm{O} \cdots \cdots\left[\mathrm{M}\left(\mathrm{H}_{2} \mathrm{O}\right)_{5}(\mathrm{OH})\right]^{(\mathrm{n} \cdot 1)+}+\mathrm{H}_{3} \mathrm{O}^{+}
$$

e reagindo fortemente com alguns tipos de rocha, em especial com aquelas que contêm carbonatos e silicatos, de carácter básico. Observa-se então a libertação de gás $\left(\mathrm{CO}_{2}\right)$ que, em alguns casos, é espectacular, quando se sobrepõe à libertação de ar em rochas porosas. Tor-na-se então necessário reforçar a receita utilizada para observar a cristalização rápida. Os exemplos mais ilustrativos são as reacções do alúmen de ferro com mármore e conchas, que ficam de cor amarelo-laranja, provavelmente devido à formaçã̃o de espécies $\left[\mathrm{Fe}\left(\mathrm{H}_{2} \mathrm{O}\right)_{5}(\mathrm{OH})\right]^{2+}$ e outros hidróxidos. Também 0 alúmen de crómio, ao reagir fortemente com carbonatos e cimento apresenta decomposição, formando um sal microcristalino verde, e só por adição de mais composto é que se consegue a sua cristralização.

\section{DESCRIÇÃO dO MÉTODO DE EXECUÇÃ̃}

As preparações devem ser feitas utilizando obrigatoriamente bata, óculos de segurança e luvas e de preferência numa hotte ou local bem ventilado. Nunca esfregue os olhos ou a pele, pois pode provocar 0 aparecimento de alergias.

Os materiais de suporte devem ser lavados préviamente e se necessário mergulhados em soluções diluidas de ácido clorídrico (1:10), para remover terra, musgo, ferrugem, etc.. Utilize uma escova, se necessário.

A receita mágica que funciona para quase todos os casos é de $100 \mathrm{~g}$ de sal para $200 \mathrm{ml}$ de solução: após pesagem, o sal é dissolvido em água destilada, a ferver, até prefazer um volume total aproximado de $200 \mathrm{ml}$. Agitar vigorosamente com uma vareta de vidro e aquecer moderadamente até dissolução completa. Não utilize recipientes ou material metálico pois poderá desencadear reacções de oxidaçãoredução e outras, contaminando as soluções. Introduza as pedras nesse mesmo recipiente, ou verta a solução para cristalizadores (ou outros recipientes) onde previamente colocou as pedras. Se trabalhar com vários tipos de pedra, separe-os por vários cristalizadores ou recipientes. Obterá melhores resultados se utilizar um balão de bocal largo, em Pyrex, pois a forma do recipiente irá diminuir a velocidade de evaporação (condensação nas paredes). Para a retardar poderá também cobrir 0 recipiente com papel de filtro perfurado. Para obter cristais de grandes dimensões, coloque o recipiente dentro de outro de maior capacidade com água quente e introduza este conjunto numa caixa de esferovite em local onde a temperatura oscile pouco. Deixe arrefecer 0 mais lentamente possivel até à temperatura ambiente e introduza depois o conjunto no frigorífico, baixando gradualmente a sua temperatura, mas sempre acima de $0^{\circ} \mathrm{C}$. Quanto mais tempo esperar, maiores dimensões atingirão os cristais. Para preparações rápidas pode dispensar o frigorífico e a caixa de esferovite. Mal se atinja a temperatura ambiente $\left(25^{\circ} \mathrm{C}\right)$ serão já visiveis os cristais. Retire-os com uma pinça, separando aqueles que se tenham aglutinado. Deixe-os secar ao ar, em cima de papel de filtro, durante um dia. Não utilize calor ou secadores, pois a grande maioria destes compostos são eflorescentes, perdendo rapidamente a água de cristalização. Depois de secos deve aplicar uma camada de verniz celulósico ou simples verniz transparente para unhas, que ajudará a fixação dos cristais e retardará a sua decomposiçăo. Lembre-se de que os cristais são solúveis em água e evite locais húmidos para os conservar. As águas mães desta preparação poderão ser utilizadas mais do que uma vez, mas os cristais de "segundas águas" não serão tão perfeitos e brilhantes. Também a pureza do sal utilizado irá repercutir-se na qualidade dos cristais obtidos. Filtre sempre à trompa a solução a reciclar ou pelo menos decante-a de resíduos resultantes da reacção com a rocha. Para acelerar a secagem pode lavar os cristais com etanol, acetona e éter etílico, mas ensaie primeiro a sua solubilidade nestes compostos.

Para os ensaios com metais, latão, arame zincado, redes metálicas, irão ocorrer reacções de oxidação-redução: por exemplo o sulfato de cobre com arame de zinco irá reduzir-se a cobre(I) e a cobre metálico, a soluçāo mudará de cor para verde, poderá ocorrer a precipitação de hidróxidos ou sais de zinco (esbranquiçados) e será visivel a libertação de hidrogénio. Estes processos irão competir com 0 processo de cristalização e para conseguir os efeitos desejados deverá usar soluções mais concentradas.

Caso esteja interessado em aumentar o tamanho dos cristais obtidos, 
poderá consegui-lo adicionando pequenas porções da solução inicial ao recipiente contendo as pedras, para compensar as perdas por evaporação. Não faça as adições a temperaturas elevadas pois poderá provocar a dissolução dos cristais já formados. Poderá prolongar este processo de crescimento durante meses como se descreve na ref.2, utilizando a rocha com cristais como "semente" em vez da conhecida técnica do fio. Tal como ai vem descrito é muito importante evitar oscilações do recipiente.

Esta receita genérica foi experimentada num laboratório durante 0 Inverno, em que a temperatura ambiente chega a atingir os três graus durante a noite. Poderá ter que ajustar estas receitas para a temperatura do seu local de trabalho. 0 emprego de soluções menos concentradas poderá levar ao aparecimento de cristais de maiores dimensões em menor número e poderá levar a efeitos especiais nos casos em que há reaç̧ões: tal é o caso do sulfato de níquel e do sulfato de cobre e amónio hidratados, em que a rocha fica coberta de pequenos microcristais adquirindo um aspecto aveludado, (a composição destes microcristais não foi determinada).

\section{OS DETALHES DO MÉTODO}

A receita genérica vem indicada no parágrafo anterior, com excepção da mistura 15 (100 g de 1 e $75 \mathrm{~g}$ de 11) e da mistura 17 ( $100 \mathrm{~g}$ de 2 e $65 \mathrm{~g}$ de 11). No entanto, para algumas das alíneas obtiveram-se cristais maiores com soluções mais diluídas (massa para $200 \mathrm{ml}$ de solução):

1 - $90 \mathrm{~g} ; 3-20 \mathrm{~g} ; 6-50 \mathrm{~g} ; 10-$ $40 \mathrm{~g} ; 11-70 \mathrm{~g} ; 12-65 \mathrm{~g} ; 16-40 \mathrm{~g}$ de 10 e $20 \mathrm{~g}$ de 12 .

Os sulfatos duplos de amónio e M" ( $M=\mathrm{Cu}$, Ni e Co) foram preparados por precipitação de uma solução (200 ml) contendo as quantidades estequiométricas do sulfato do metal e de sulfato de amónio $(0.22,0.10$ e 0.11 moles para 0 $\mathrm{CuSO}_{4} \cdot 5 \mathrm{H}_{2} \mathrm{O}, \mathrm{NiSO}_{4} \cdot 6 \mathrm{H}_{2} \mathrm{O}$ e $\mathrm{CoSO}_{4} \cdot 7 \mathrm{H}_{2} \mathrm{O}$ respectivamente).

\section{AS EXPERIÊNCIAS FALHADAS}

Se tenciona explorar mais compostos, verifique primeiro se se encon- tram comercializados e quais as suas propriedades [3]. Evite os que são deliquescentes, tais como os nitratos de cobre, níquel, cobalto(II), o cloreto e 0 sulfato de cobalto(II), etc., pois mesmo que cristalizem bem, não os poderá preservar. 0 mesmo é extensivo a compostos sensiveis à luz ou facilmente oxidáveis como 0 são, por exemplo, os sais de ferro(II). Quanto à preservação dos que aqui foram apresentados, para além do que acima se disse, poderá recuperar alguns dos cristais eflorescentes se os mergulhar de novo numa solução saturada por algumas horas. A longo prazo os que oferecem mais garantias são 0 alúmen de potássio e 0 sulfato de cobre.

Com as experiências "falhadas", ou seja, com as pedras em que apenas obteve microcristais, poderá ainda obter jardins químicos [4] espectaculares com os cristais de silicatos crescendo sobre as pedras: para isso mergulhe as pedras com os microcristais numa solução de silicato de sódio a 40\% (p/p) num recipiente de vidro de forma alta e deixe-0 em repouso. Poderá ainda adicionar outros sais hidratados ao conjunto, tais como nitratos, cloretos, acetatos dos metais acima indicados e também de ferro (II). (III) e de manganês(II).

\section{UMA PROPOSTA DE ENSINO}

Com este método o professor poderá introduzir uma grande diversidade de conceitos básicos, para além das técnicas elementares envolvidas numa recristalização, ou seja, pesagem, dissolução, filtração à trompa, lavagem de precipitados e secagem. A lista de conceitos é demasiado vasta para que possamos dar-Ihe uma orientação especifica, a qual irá depender, com é óbvio, do grau de preparação dos alunos. Limitamo-nos, assim, a fazer uma listagem tão completa quanto possivel desses conceitos, deixando ao leitor o cuidado da sua escolha:

- misturas, soluções e processos para exprimir concentrações;

- solubilidade em água de compostos iónicos, forças intermoleculares, variação da solubilidade com a temperatura, dissoluções endotérmicas e exotérmicas:

— soluções saturadas, produtos de solubilidade, reacções de precipitação;
- compostos anidros e hidratados, água de cristalização, substâncias higroscópicas, deliquescentes e eflorescentes;

- reacções de ácido-base, a noção e medição de $\mathrm{pH}, 0$ ataque de carbonatos em meio ácido;

- noção de composto de coordenação, aquocomplexos e 0 seu carácter ácido; a origem da cor de complexos de metais de transição;

— reacções de oxidação-redução, oxidantes e redutores.

Poderá ainda introduzir os princípios básicos da famosa "marcha de análise", utilizando as misturas de sais acima descritas, para identificação dos catiões metálicos envolvidos, como por exemplo, a reacção do aluminon com 0 aluminio(III), a reacção do niquel(II) com a dimetilglioxima, a reacção do cobre(II) com 0 iodeto de potássio, etc.

\section{AGRADECIMENTOS}

Agradecemos à Universidade dos Açores, Departamento de Ciências Agrárias, 0 envio de pedras vulcânicas e ao Instituto Superior Técnico, Departamento de Química, o financiamento deste trabalho. Ao Eng ${ }^{0} \mathrm{~F}$. Marques Dias, do Centro de Electrodinâmica do Complexo Interdisciplinar I, agradecemos a execução das fotografias.

${ }^{1}$ Dep. de Eng. Química, Instituto Superior Técnico, Av. Rovisco Pais 1096 Lisboa Codex

\section{BIBLIOGRAFIA}

1. A. Holden, P. Singer, Crystal and Crystal Growing, Doubleday Anchor Books, New York, 1960, p 93-104.

2. L.Mullin, Chemistry Experiments for Children, Dover Publications, Inc., New York, 1968.

3. M.Windholz, S.Budavai, R.S. Blumetti, E.S. Otterbein, ed. The Merck Index, 10th ed., Merck \& Co. Inc., New York, 1983.

4. D. B. Phillips, J.Chem. Educ., 65, (1988) 453. 


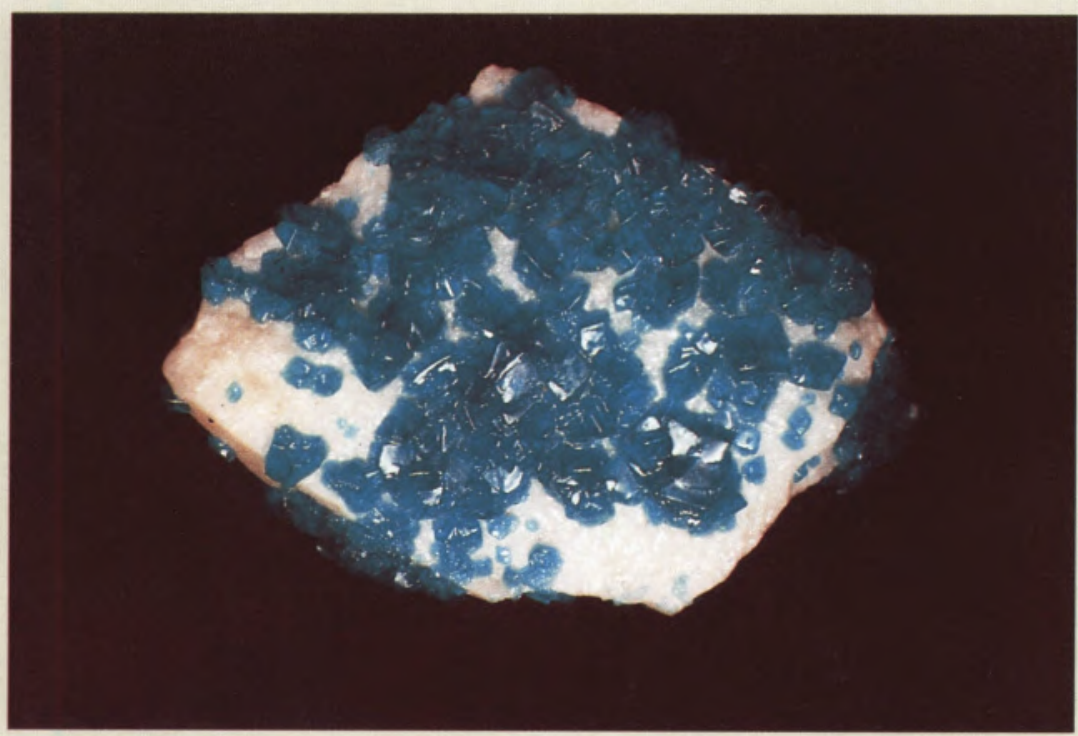

Figura a). $\left(\mathrm{NH}_{4}\right)_{2} \mathrm{Ni}\left(\mathrm{SO}_{4}\right)_{2} \cdot 6 \mathrm{H}_{2} \mathrm{O}$

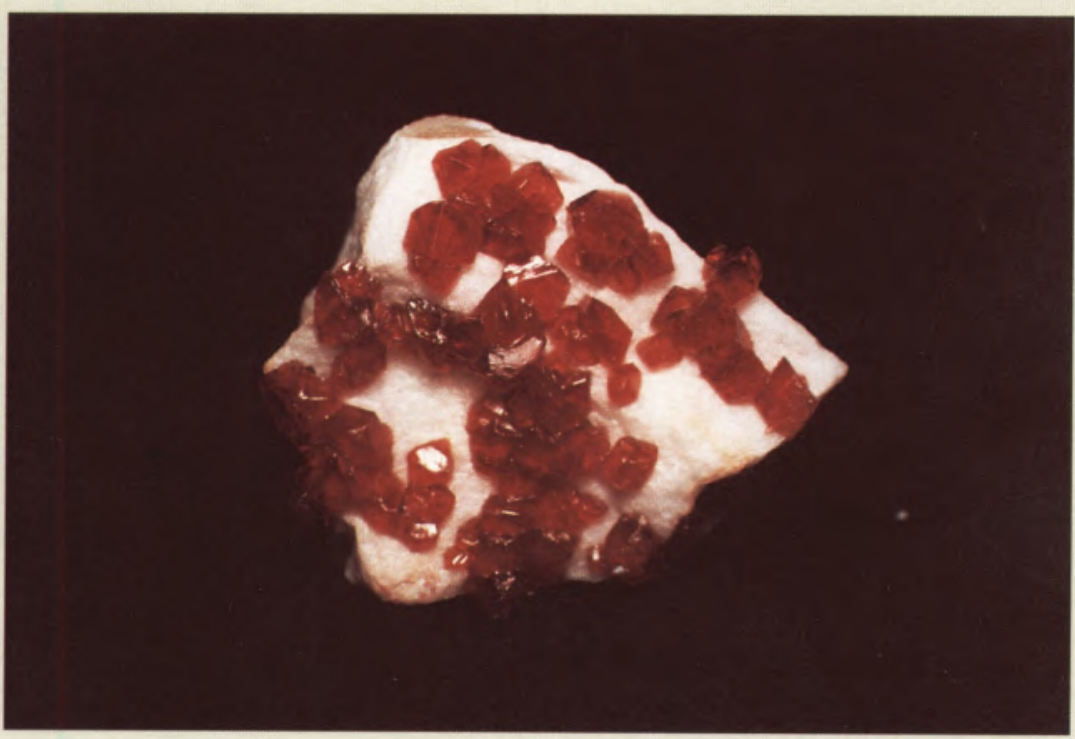

Figura b). $\left(\mathrm{NH}_{4}\right)_{2} \mathrm{Co}\left(\mathrm{SO}_{4}\right)_{2} \cdot 6 \mathrm{H}_{2} \mathrm{O}$

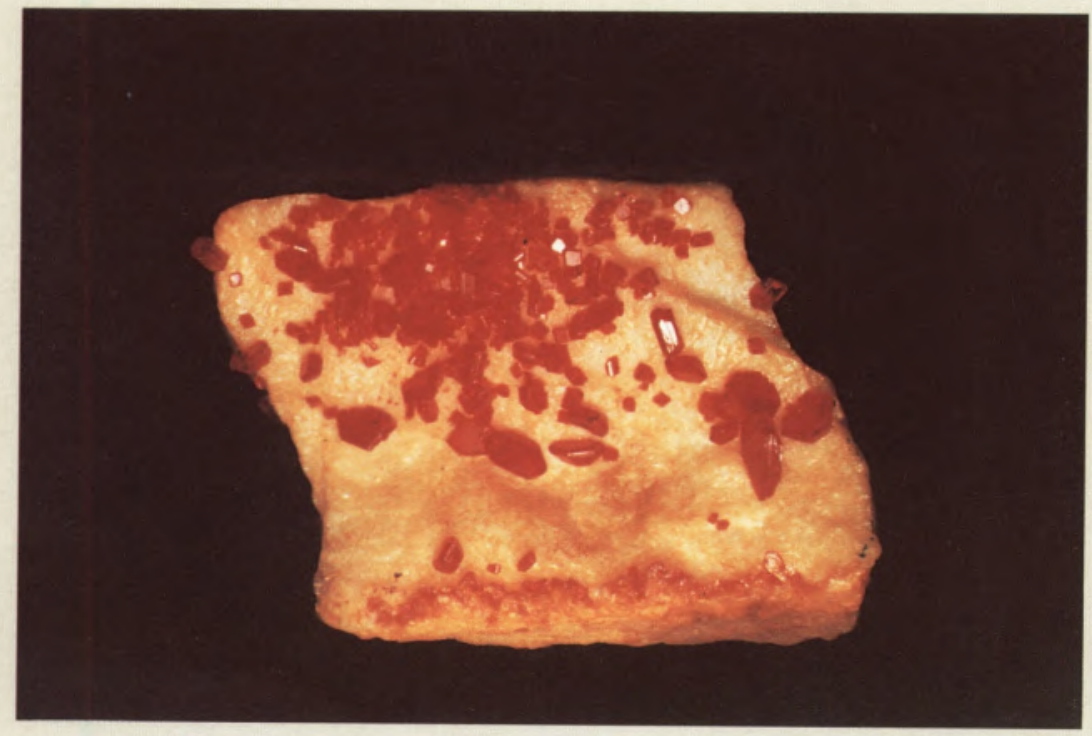




\section{e n s i n 0}

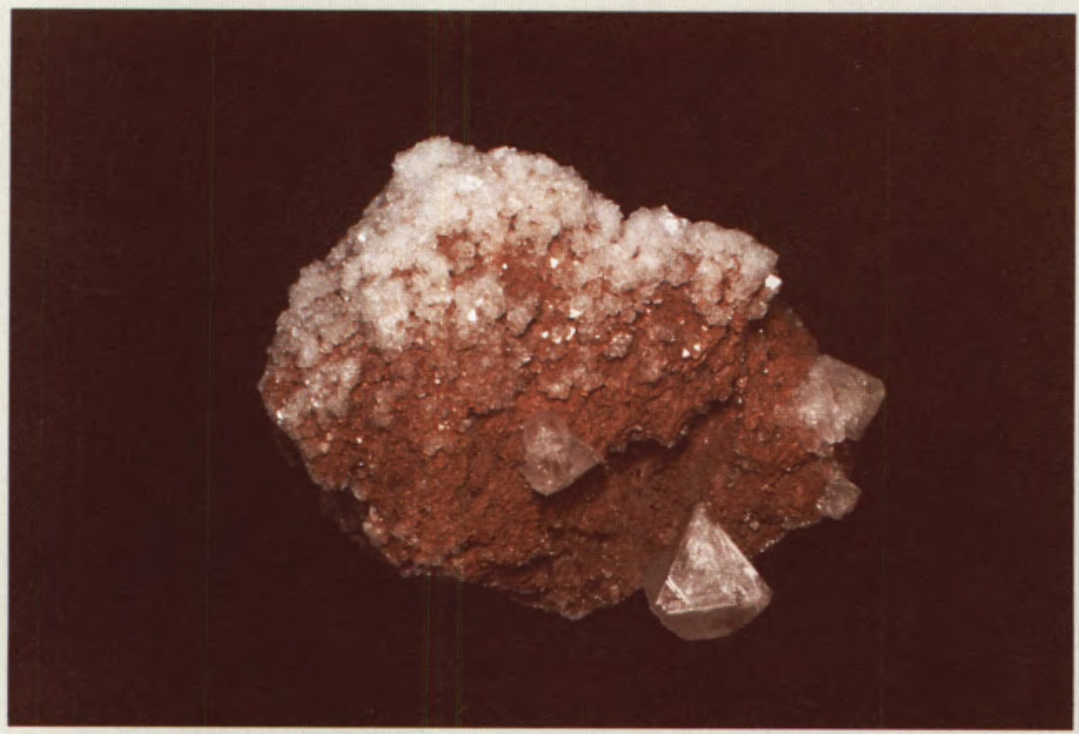

Figura d). Alúmen de potássio $\mathrm{KAl}\left(\mathrm{SO}_{4}\right)_{2} \cdot 12 \mathrm{H}_{2} \mathrm{O}$

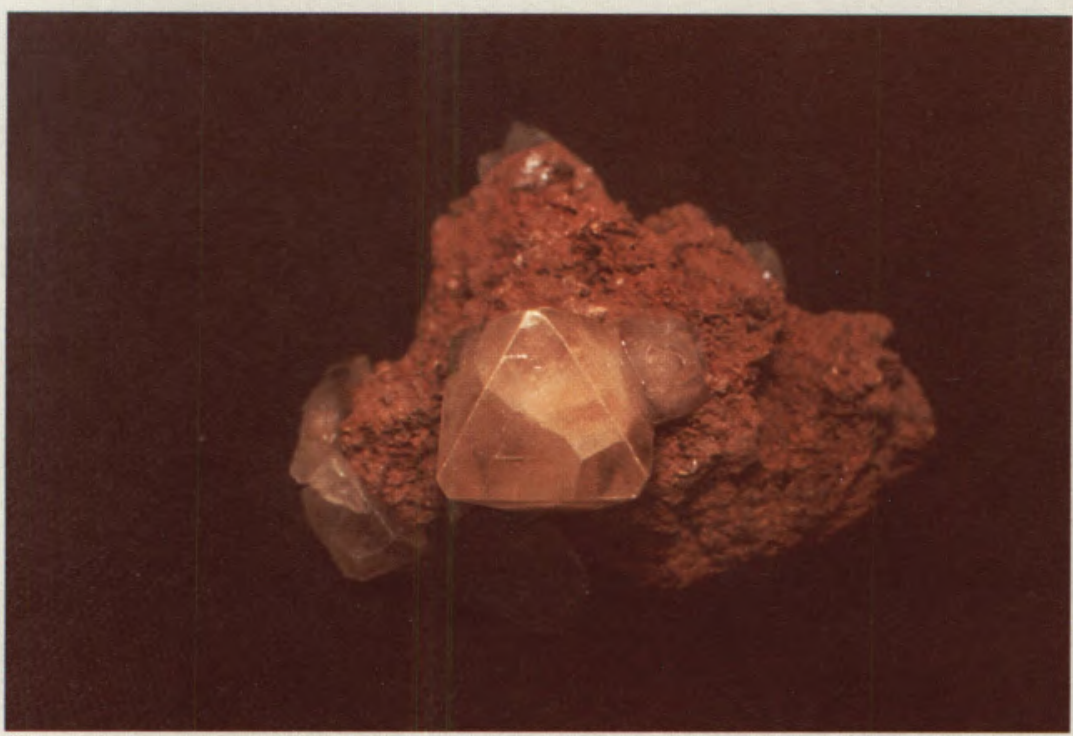

Figura e). Alúmen de ferro $\left(\mathrm{NH}_{4}\right) \mathrm{Fe}\left(\mathrm{SO}_{4}\right)_{2} \cdot 12 \mathrm{H}_{2} \mathrm{O}$

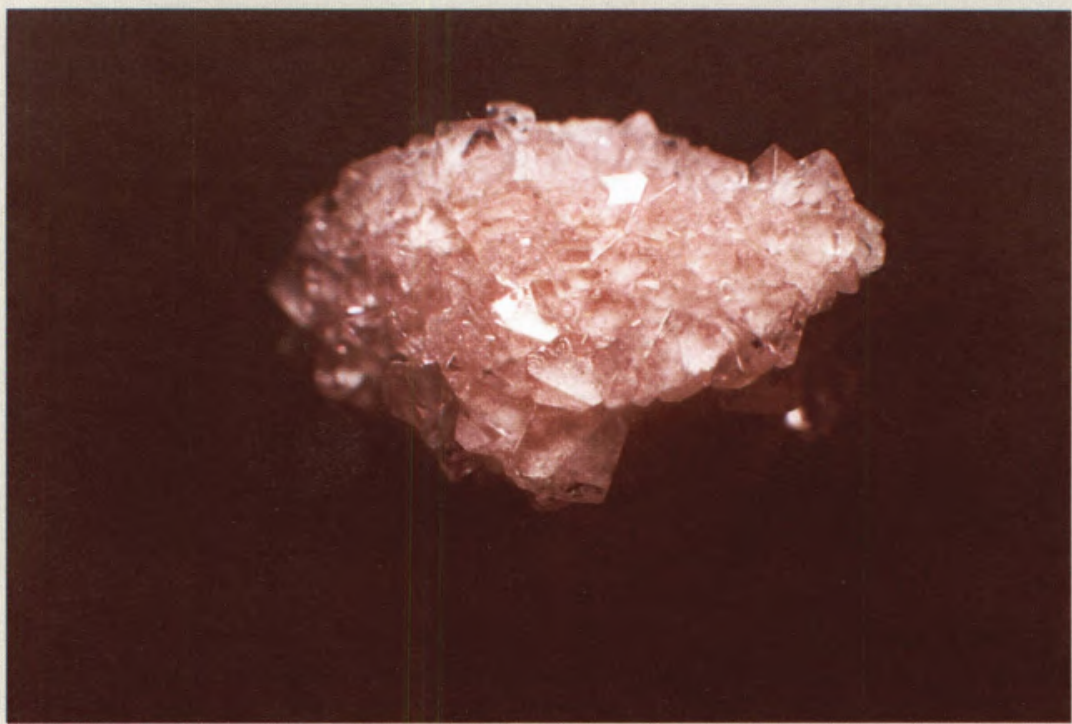

Figura f). Mistura de alúmens de potássio $\mathrm{KAl}\left(\mathrm{SO}_{4}\right)_{2} \cdot 12 \mathrm{H}_{2} \mathrm{O}$ e de crómio $\mathrm{Cr}\left(\mathrm{SO}_{4}\right)_{2} \cdot 12 \mathrm{H}_{2} \mathrm{O}$ 


\section{Superior sensibilidade GC/MS para qualquer amostra.}

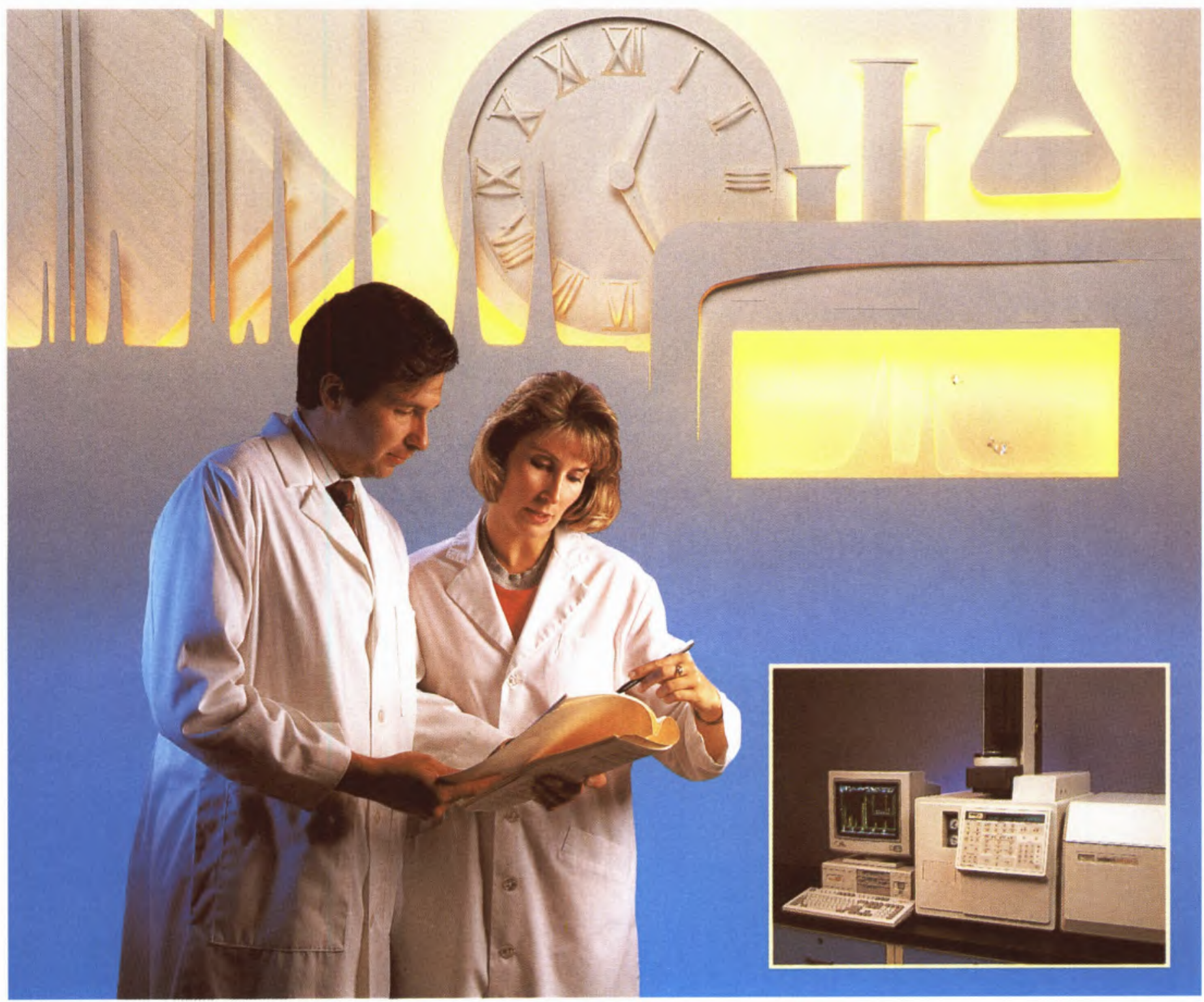

A nova PLACA-ELECTRÓNICA (WAVE-BOARD) aplicada no SATURN 3 introduz padrôes que nenhum quadrupolo de bancada é capaz de igualar.

De certeza que não estará interessado em comprar um novo GC/MS de bancada sem primeiro se inteirar da nova tecnologia da Placa Electrónica (WAVE-BOARD) usada no SATURN 3.
Esta proporciona a

sensibilidade e selectividade que precisa mesmo quando das mais complexas aplicações.

Peça-nos literatura e lista de referências. varian $\circledast$

Representantes:

EMÍLIO DE AZEVEDO CAMPOS \& CA., LDA

NO PORTO

Rua Senhora da Penha, 110-114

4450 Matosinhos

Telef.: (02) 9531183

Fax: (02) 9531430

EM LISBOA

Rua Antero de Quental, 17-10 / 1100 Lisboa Telef.: (01) 3520194

Fax: (01) 353382 